\title{
ARACTERÍSTICAS MORFOLÓGICAS E QUÍMICAS DE LÂMINAS foliares de PASPALUM SPP.
}

\author{
Keila Cortez de Lucena \\ Universidade Federal da Grande Dourados, Rodovia Dourados-Itahum, Km 12, CEP: \\ 79804-970, Dourados, MS, Brasil. E-mail: keila@ajurycaba.com.br
}

\section{Gisele Catian}

Universidade Federal de Mato Grosso do sul, Instituto de Biociências, Avenida Costa e Silva, s/n - Cidade Universitária, CEP: 79070-900, Campo Grande, MS, Brasil.

E-mail: gcatian@gmail.com

\author{
BEATRIZ LEMPP \\ Universidade Federal da Grande Dourados, Departamento de Ciências Agrárias, Rodovia Dou- \\ rados-Itahum, Km 12, CEP: 79804-970, Dourados, MS, Brasil. \\ E-mail: beatrizlempp@ufgd.edu.br
}

\begin{abstract}
Resumo: O objetivo deste trabalho foi avaliar o potencial de utilização de lâminas foliares da gramínea tropical Paspalum spp. para o consumo animal por meio das características morfofisiológicas, da anatomia quantitativa e das características químicas. O experimento foi realizado no período de agosto de 2009 a junho de 2010, no município de Dourados - MS. Foram avaliadas oito espécies de Paspalum spp., sendo as sementes cedidas pela Embrapa Pecuária Sudeste. O delineamento experimental utilizado foi o de blocos ao acaso, com quatro repetições. As médias das características foram agrupadas pelo teste Scott-Knott. Foram evidenciados genótipos com potencial para forrageamento. Paspalum malacophyllum destacou-se em relação às características morfofisiológicas, químicas e anatômicas. Para as características anatômicas com proporções de tecidos de maior qualidade, o genótipo Paspalum glaucescens também se destacou, apresentando altas proporções de mesofilo e bainha parenquimática dos feixes. As avaliações anatômicas de lâminas foliares de Paspalum spp. indicaram importantes diferenças entre os genótipos quanto à proporção e à composição de tecidos.
\end{abstract}

Palavras-chave: Digestibilidade, Forrageira, Gramínea.

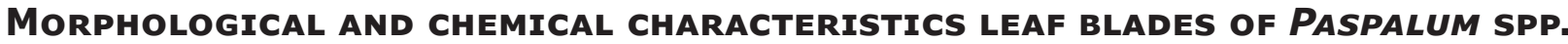

Abstract: The objective of this study was to evaluate the potential of using the leaf blades tropical grasses of Paspalum spp. for animal consumption by means of morphological and physiological characteristics, quantitative anatomy and chemical characteristics. The experiment was conducted from August 2009 to June 2010, in the municipality of Dourados/MS. We evaluated eight Paspalum spp. species and the seeds were provided by Embrapa Pecuária Sudeste. The experimental design was a randomized block design with four replications. The means of the features were grouped by the Scott-Knott test. We observed genotypes with potential for foraging. Paspalum malacophyllum stood out the by morphophysiological, chemical and anatomical characteristics. For the anatomical features with higher quality tissue proportions, the Paspalum glaucescens stood out, with high proportions of mesophyll and parenchyma bundle sheath. Anatomical reviews of leaf blade Paspalum spp. indicated significant differences among genotypes in proportion and tissue composition.

Keywords: Digestibility, Forage, Grass. 


\section{INTRODUÇÃO}

aspalum abrange inúmeras espécies de gramíneas forrageiras nativas da América do Sul (Zuloaga \& Morrone, 2005), sendo objeto de estudos citológicos e taxonômicos (Canto-Dorow, Longhi-Wagner \& Vall, 1996; Oliveira \& Valls, 2002). O gênero tem o Centro-Oeste como principal centro de diversidade de espécies, apresentando maior ocorrência no Brasil (Filgueiras et al., 2010; Valls \& Oliveira, 2012). Compreende mais de 400 espécies tropicais e subtropicais (Quarín \& Hanna, 1980), cuja importância é evidenciada por sua adaptabilidade a diferentes ecossistemas, devido à grande diversidade genética existente (Strapasson, Vencovsky \& Batista, 2000). Com isso, a importância como pastagem cultivada vem sendo evidenciada em razão da ampla variabilidade inter e intraespecífica.

Estudos da anatomia das lâminas foliares de Paspalum têm sido conduzidos no sentido de auxiliar trabalhos taxonômicos de revisões dos grupos informais do gênero (Aliscioni \& Arriaga, 1998; Morrone, Vega \& Zuloaga, 1996; Morrone, Denham \& Zuloaga, 2004) ou simplesmente descrições morfológicas e anatômicas (Aliscioni \& Denhan, 2008; Baréa et al. 2006; Camacho de Torres, Rodriguez \& Guevara, 1999; Ogie-Odia et al., 2010; Scheffer-Basso, Rodrigues \& Bordignon, 2002). As gramíneas forrageiras são a base da alimentação de ruminantes no Brasil, por isso, estudos que avaliem a variação nas características morfológicas e de composição química desta fonte de alimento auxiliam o sistema pecuário.

Os fatores que interferem na qualidade das gramíneas forrageiras podem ser de origem físico-química, relacionados à morfologia da vegetação, também quanto ao seu valor nutricional e desempenho animal, pois estas características apresentam potenciais digestivos diferenciados, referentes à proporção de tecidos dispostos no limbo foliar (Brito et al., 1999). Devido à baixa qualidade de valor nutritivo de gramíneas exóticas, estudos com espécies forrageiras nativas auxiliam na utilização de espécimes para a diversificação genética.

O objetivo deste trabalho foi avaliar o potencial qualitativo (arranjo, disposição, quantidade de células da epiderme e mesofilo), verificar os tecidos lignificados que podem interferir no valor nutricional da planta e analisar as características morfofisiológicas, anatômicas e químicas das lâminas foliares de oito espécies de Paspalum.

\section{MATERIAL e MÉtodos}

O experimento foi conduzido nas dependências da Faculdade de Ciências Agrárias da Universidade Federal da Grande Dourados, localizada no município de Dourados - MS, no ponto de coordenadas $\left(22^{\circ} 17^{\prime} 56,50^{\prime \prime} \mathrm{S}, 54^{\circ} 49^{\prime} 02,12^{\prime \prime} \mathrm{W}, 416 \mathrm{~m}\right)$.
As avaliações morfofisiológicas e anatômicas dos genótipos foram realizadas no laboratório de Forragicultura da Faculdade de Ciências Agrárias e as análises de composição química, na Embrapa Pecuária Sudeste, São Carlos - SP, no ponto de

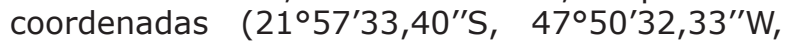
$841 \mathrm{~m}$ ), entre o período de agosto de 2009 e junho de 2010.

As sementes de Paspalum spp. foram cedidas pela Embrapa Pecuária Sudeste, filiada à Rede Nacional de Avaliação de Paspalum spp. para o desenvolvimento e a obtenção de novos cultivares, sendo utilizadas as seguintes sementes: Paspalum malacophyllum, Paspalum glaucescens, Paspalum guenoarum 1, Paspalum guenoarum 2, Paspalum sp.1, Paspalum sp.2, Paspalum regnelii e Paspalum atratum cv. Pojuca.

Utilizaram-se vasos de polietileno com $5 \mathrm{~kg}$ de substrato contendo terra peneirada em peneira de $2 \mathrm{~mm}$. O solo utilizado foi Latossolo Vermelho Distrófico textura média, coletado na rodovia Dourados-Itahum, no ponto de coordenadas (22013'16"S, 54017'01"W, $452 \mathrm{~m}$ ). O solo experimental apresentou as seguintes características químicas: matéria orgânica $(\mathrm{MO})=8,1 \mathrm{~g} /$ $\mathrm{dm}^{3} ; \mathrm{pH}\left(\mathrm{CaCl}_{2}\right)=4,4 ; \mathrm{pH}\left(\mathrm{H}_{2} \mathrm{O}\right)=5,3$; fósforo $(P)=9,0 \mathrm{mg} / \mathrm{dm}^{3} ;$ potássio $(\mathrm{K})=0,4 \mathrm{mmol}_{\mathrm{cc}}$ $\mathrm{dm}^{3}$; alumínio $(\mathrm{Al})=5,5 \mathrm{mmol}_{\mathrm{cc}} / \mathrm{dm}^{3}$; cálcio $(\mathrm{Ca})$ $=9,4 \mathrm{mmol}_{\mathrm{cc}} / \mathrm{dm}^{3}$; magnésio $(\mathrm{Mg})=2,3 \mathrm{mmol}_{\mathrm{cc}} /$ $\mathrm{dm}^{3}$; soma de bases $(\mathrm{SB})=12,1 \mathrm{mmol}_{\mathrm{cc}} / \mathrm{dm}^{3}$; $\mathrm{CTCpH}_{7,0}(\mathrm{~T})=43,1 \mathrm{mmol}{ }_{\mathrm{cc}} / \mathrm{dm}^{3}$; saturação por bases na $\mathrm{CTCpH}_{7,0}(\mathrm{~V} \%)=28$.

O solo foi incubado com calcário dolomítico em agosto de 2009 (1,724 t. ha-1 ou 4,310 g/5 Kg de solo) e irrigado a cada sete dias, completando-se o volume para $5,7 \mathrm{~kg}$. O volume de água foi calculado em função da perda e para o preenchimento de $60 \%$ dos poros. A adubação foi feita por meio de solução nutritiva, aplicada a um volume de $50 \mathrm{ml}$ por vaso, com NPK (Nitrogênio, Fósforo e Potássio) e micronutrientes, usando como fontes de nutrientes os seguintes compostos químicos: ureia, sulfato de amônio, superfosfato simples, ácido bórico, sulfato cúprico, cloreto de potássio, cloreto de manganês, sulfato ferroso, molibdato de sódio, sulfato de zinco e ácido cítrico, conforme resultados da análise química e de recomendação para Paspalum atratum Sw. (Vilela, Barcellos \& Andrade, 2001). A semeadura foi realizada em novembro de 2009, utilizando-se cinco sementes por vaso.

Utilizou-se o delineamento experimental de blocos casualizados com quatro repetições. Efetuou-se o desbaste visando ter três plantas/vaso. O corte de uniformização da forragem foi a 10 $\mathrm{cm}$ do solo em dezembro de 2009. Efetuaram-se quatro amostragens das lâminas foliares para 0 estudo em intervalos de 35 dias (fevereiro, abril, maio e junho de 2010) e, ao final, as plantas foram desfolhadas a $10 \mathrm{~cm}$ do solo.

Para a avaliação das características morfofisiológicas, foram utilizadas cinco lâminas foliares expandidas (exposição da lígula) dos perfilhos 
primários. Mediram-se: comprimento, largura e área foliar por meio de medidor de área foliar ( $\mathrm{Li}$ - Cor Leaf Area Index Meter). As lâminas foliares foram levadas à estufa a $55 \pm 5^{\circ} \mathrm{C}$ para secagem até peso constante, a fim de se estimar o teor de massa seca (MS). A área foliar específica (AFE = $\mathrm{cm}^{2} / \mathrm{g}$ ) foi estimada segundo Radford (1967).

Para a avaliação anatômica, as lâminas foliares, quatro fragmentos por repetição, foram acondicionadas em solução de formalina-ácido acético-álcool etílico (FAA 50\%) e processadas segundo Daykin e Hussey (1985). Após a inclu-

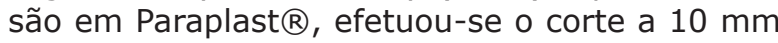
de espessura e a coloração quádrupla triarca dos tecidos (Hagquist, 1974). A reação positiva com a safranina foi atribuída à presença de lignina e também, quando positiva na epiderme adaxial e abaxial, à presença de outros compostos fenólicos (Johansen, 1940), como tanino no conteúdo celular da epiderme (Lempp, 2007).

A mensuração dos tecidos foi efetuada por meio de sistema analisador de imagens, acoplado a um microscópio binocular. Para a verificação das áreas dos tecidos, inicialmente, mensurou-se toda a área da seção transversal projetada no vídeo - face adaxial e abaxial da epiderme, bainha parenquimática dos feixes vasculares, esclerênquima, tecido vascular e parênquima clorofiliano, este último calculado por diferença com as demais medidas. As amostras de lâminas foliares foram submetidas às análises químicas por meio de espectroscopia de reflectância do infravermeIho próximo (NIRS), de acordo com os procedimentos de Marten, Shenk \& Barton (1985).

Nas lâminas foliares de cada corte, verificaram-se os teores de proteína bruta (PB), de acor- do com a Association of Official Analytical Chemists (AOAC, 1990), fibra em detergente neutro (FDN), fibra em detergente ácido (FDA) e lignina em ácido sulfúrico (Van Soest, Robertson \& Lewis, 1991).

As médias dos valores obtidos em análises morfofisiológicas, químicas e anatômicas foram comparadas pelo teste de Scott-Knott a 5\% de probabilidade por meio do programa computacional Sisvar (2003).

\section{Resultados e discussão}

\section{CARACTERÍSTICAS MORFOFISIOLÓGICAS}

Paspalum malacophyllum Trin. apresentou a maior largura da lâmina foliar (Tab. 1), a qual está diretamente associada à quantidade de parênquima clorofiliano que compõem o mesofilo, sendo este de preferência animal e importante do ponto de vista qualitativo, como tecido nutritivo e digerível (Akin, 1979). A mesma espécie apresentou a maior média de área foliar (AF) e de área foliar específica (AFE). A AF é a relação direta entre o comprimento e a largura das lâminas foliares e, além de facilitar a discriminação dos genótipos, pode ser um indicativo de potencial qualitativo da forrageira para o uso em alimentação animal. Já o maior comprimento das lâminas foliares ocorreu em $P$. glaucescens. Lâminas foliares maiores podem não apresentar grandes quantidades de tecido parenquimático no mesofilo, com isso o comprimento da lâmina foliar pode estar correlacionado negativamente à digestibilidade animal (Masaoka, Wilson \& Hacker, 1991), reflexo da AFE menor de folhas compridas e finas.

Tab. 1. Características morfofisiológicas de lâminas foliares de genótipos de Paspalum spp.

\begin{tabular}{|c|c|c|c|c|}
\hline ESPÉCIE & LARGURA (CM) & $\begin{array}{l}\text { COMPRIMENTO } \\
\text { (CM) }\end{array}$ & $\begin{array}{l}\text { ÁREA FOLIAR } \\
\quad(\mathrm{CM} 2)\end{array}$ & $\begin{array}{l}\text { ÁREA FOLIAR ESPECÍFICA } \\
(\mathrm{CM} 2 / \mathrm{G})\end{array}$ \\
\hline P. Glucescens & $1,11 \mathrm{c}$ & $27,83 \mathrm{~A}$ & $97,96 \mathrm{~B}$ & $188,31 c$ \\
\hline Paspalum sp. 1 & $1,14 \mathrm{C}$ & $26,06 A$ & $88,99 в$ & $150,41 c$ \\
\hline Paspalum sp. 2 & $0,67 \mathrm{E}$ & $23,16 \mathrm{~B}$ & $51,20 \mathrm{D}$ & $177,83 c$ \\
\hline P. Guenoarum & $0,92 \mathrm{D}$ & $26,72 \mathrm{~A}$ & $70,39 c$ & $176,07 c$ \\
\hline P. Regnellii & 1,39 в & $22,92 \mathrm{~B}$ & 98,29 в & 240,27 в \\
\hline P. Malocophyllum & $3,24 \mathrm{~A}$ & $17,49 \mathrm{c}$ & $141,67 \mathrm{~A}$ & $273,94 \mathrm{~A}$ \\
\hline P. Guenoarum & $0,81 \mathrm{D}$ & $26,36 \mathrm{~A}$ & $72,92 c$ & $185,17 c$ \\
\hline P. Atratum & $1,37 \mathrm{~B}$ & $27,45 \mathrm{~A}$ & $109,56 \mathrm{~B}$ & $167,43 c$ \\
\hline CV(\%) & 8,53 & 12,45 & 13,31 & 10,81 \\
\hline MÉDIA/DP & $1,33 \pm 0,8$ & $24,75 \pm 3,4$ & $91,37 \pm 27,6$ & $194,93 \pm 41$ \\
\hline
\end{tabular}

*Médias seguidas de mesma letra na mesma coluna não diferem entre si a $5 \%$ de probabilidade, pelo teste de agrupamento de médias Scott-Knott. $C V=$ coeficiente de variação, $D P=$ desvio padrão. Genótipos em ordem de citação na tabela: (BRA-011401), (BRA-011681), (BRA-012700), (BRA-014851), (BRA-019186), (BRA-003077), (BRA006572), (BRA-009610). 


\section{Características químicas}

Paspalum malacophyllum apresentou o maior valor para proteína bruta (PB), sendo que o menor teor observado ocorre em $P$. atratum (Tab. 2 ). Valores de PB superiores a $7 \%$ são necessários para 0 atendimento das exigências dos microorganismos ruminais (Van Soest, 1994), o que também foi observado em Paspalum repens (Ell.) Kunth por Cardoso et al. (2006).

A digestibilidade das lâminas foliares diminui com teores de PB inferiores ao citado, pelo fato de o nitrogênio não ser suficiente para garantir um ambiente ruminal adequado aos microorganismos (Moore \& Mott, 1973), o que implicará reduções no consumo voluntário e no desempenho animal (Sniffen et al., 1993), qualificando $P$. malacophyllum para o consumo. De acordo com Merchen \& Bourquin (1994), maiores teores de PB contribuem para o aumento da superfície celular do mesofilo, tornando as lâminas foliares mais suscetíveis à ação dos microorganismos.

Menores teores de fibra em detergente neutro (FDN), fibra em detergente ácido (FDA) e lignina (LIG) destacaram as lâminas foliares de P. mala- cophyllum. Plantas com maiores teores de FDN teriam menor potencial de consumo, devido ao isolamento completo dos constituintes fibrosos que não apresentam características ideais, como teor de lignina e carboidratos estruturais para a fermentação ruminal, relacionando-se com o consumo máximo de massa seca pelos animais (Mertens, 1994). Já a lignina é o primeiro fator que limita a degradabilidade da parede celular de forrageiras, pois é o componente que restringe a digestão ruminal dos polissacarídeos da parede celular (Jung \& Deetz, 1993). Com isso, o fato de esta espécie apresentar maior valor de PB e menores de FDN, FDA e LIG denota acessibilidade dos microorganismos aos nutrientes presentes nas células.

O genótipo, a morfologia e o nível de maturidade são alguns dos fatores que interferem nos componentes da parede celular das forrageiras, como Paspalum spp. (Scheffer-Basso \& Gallo, 2008), além da intensidade e da frequência da desfolhação e de fatores ambientais, sendo que o componente genotípico e morfológico pode ser o fator interferente neste estudo.

Tab.2. Características químicas de lâminas foliares de genótipos de Paspalum spp.

\begin{tabular}{lcccc}
\hline ESPÉCIE & $\mathrm{PB}(\% \mathrm{MS})$ & $\mathrm{FDN}(\% \mathrm{MS})$ & $\mathrm{FDA}(\% \mathrm{MS})$ & $\mathrm{LIG}\left(\mathrm{H}_{2} \mathrm{SO}_{4}\right)(\% \mathrm{MS})$ \\
\hline P. Glucescens & $8,34^{\mathrm{A}}$ & $70,76^{\mathrm{A}}$ & $38,00^{\mathrm{B}}$ & $4,05^{\mathrm{B}}$ \\
PASPALUM SP.1 & $7,14^{\mathrm{B}}$ & $62,42^{\mathrm{D}}$ & $33,46^{\mathrm{C}}$ & $3,42^{\mathrm{B}}$ \\
PASPALUM SP.2 & $8,23^{\mathrm{A}}$ & $61,82^{\mathrm{D}}$ & $33,17^{\mathrm{c}}$ & $3,41^{\mathrm{B}}$ \\
P. Guenoarum & $7,1^{\mathrm{B}}$ & $61,07^{\mathrm{E}}$ & $32,79^{\mathrm{c}}$ & $2,85^{\mathrm{c}}$ \\
P. Regnellii & $7,9^{\mathrm{A}}$ & $66,34^{\mathrm{B}}$ & $43,35^{\mathrm{A}}$ & $5,35^{\mathrm{A}}$ \\
P. Malocophyllum & $8,45^{\mathrm{A}}$ & $59,57^{\mathrm{E}}$ & $32,34^{\mathrm{c}}$ & $2,73^{\mathrm{c}}$ \\
P. Guenoarum & $7,82^{\mathrm{A}}$ & $64,32^{\mathrm{c}}$ & $35,76^{\mathrm{B}}$ & $3,49^{\mathrm{B}}$ \\
P. Atratum & $6,80^{\mathrm{B}}$ & $59,56^{\mathrm{E}}$ & $36,42^{\mathrm{B}}$ & $3,52^{\mathrm{B}}$ \\
\hline CV(\%) & 6,44 & 1,93 & 7,15 & 10,79 \\
\hline MÉDIA/DP & $7,73 \pm 0,63$ & $63,23 \pm 3,81$ & $35,66 \pm 3,7$ & $3,60 \pm 0,82$ \\
\hline
\end{tabular}

*Médias seguidas de mesma letra na mesma coluna não diferem entre si a $5 \%$ de probabilidade, pelo teste de agrupamento de médias Scott-Knott. PB=proteína bruta, FDN=fibra em detergente neutro, FDA=fibra em detergente ácido, $\operatorname{LIG}\left(\mathrm{H}_{2} \mathrm{SO}_{4}\right)=$ lignina (ácido sulfúrico), $\mathrm{CV}=$ coeficiente de variação, $\mathrm{DP}=$ desvio padrão. Genótipos em ordem de citação na tabela: (BRA-011401), (BRA-011681), (BRA-012700), (BRA-014851), (BRA-019186), (BRA-003077), (BRA-006572), (BRA-009610).

\section{Anatomia}

Há maior variação na epiderme adaxial (EPD) (Tab. 3), sendo que Paspalum sp.1 apresenta a maior proporção (Fig. 1A) e Paspalum glaucescens a menor (Fig. 1B), entretanto P. malacophyllum (Fig. 1C) está dentro do grupo com maiores valores de EPD e menores de EPB. Altas proporções de EPD podem interferir no potencial qualitativo da forrageira, pois as células que a compõem podem conter lignina, sílica e tanino. As maiores variações na epiderme ocorrem na face adaxial, devido à presença de células buliformes (Fig. 1A-F). Menores variações entre as espécies foram observadas para a epiderme abaxial (EPB) em relação à EPD (Tab. 3, CV\% $=6,49$ e 6,79, respectivamente). As células da EPB e EPD são parcialmente digeridas no rúmen, pois apresentam parede espessa com uma camada de cutícula, em torno de 0,5 $\mu \mathrm{m}$ (Mauseth, 1988). Entretanto, em P. malacophyllum, não foi 
observada cutícula espessa e lignina nas células buliformes (Fig. 1C). Segundo Harbers, Brazle \& Rainten (1981), as células da epiderme podem apresentar alto teor de sílica na cutícula, atuando como barreira física para a colonização dos microorganismos ruminais nos fragmentos das lâminas foliares.

A média $(46,2 \%)$ observada para epiderme geral (EPG) em relação a outras gramíneas tropicais é alta, a exemplo de várias forrageiras observadas por Paciullo et al. (2002) e de Panicum maximum Jacq. por Gomes et al. (2011). PaspaIum sp. 1 apresenta o maior EPG e não foi incluído em nenhum grupo com maiores teores de PB e menores de FDN, FDA e LIG. A alta proporção de EPG se dá principalmente em função das células buliformes, que se apresentam bem desenvolvidas. Segundo Caro \& Sanches (1969), suas características químicas são semelhantes às das células que compõem o mesofilo. No entanto, em Paspalum sp.1, Paspalum sp.2 e $P$. regnelii, observa-se grande quantidade de tanino (Fig. 1D) nessa região. Essa substância estava ausente em
P. malacophyllum. O alto teor de tanino condensado é considerado fator antinutricional para ruminantes (Barry \& Duncan, 1984) e, apesar de não ter sido quantificado, sabe-se que esta substância interfere negativamente no potencial qualitativo das lâminas foliares. Além disso, a lignina presente nestas células interfere negativamente, diminuindo a sua taxa de digestão (Harbers, Brazle \& Rainten, 1981).

Com uma área foliar maior, a área relativa da epiderme pode diminuir, um benefício em termos nutricionais, tendo em vista que as paredes externas da epiderme, à medida que se desenvolvem, tornam-se espessas, lignificadas e cobertas por uma camada de cutícula e cera, dificultando a digestibilidade, o que é mais pronunciado na EPB do que na EPD (Wilson, 1993). Como P. malacophyllum apresenta lâminas foliares mais largas, pode apresentar maior potencial qualitativo. Segundo Akin (1979), as células da epiderme apresentam paredes mais espessas e são parciais e lentamente digeridas.

Tab. 3. Proporção relativa (\%) em secção transversal, de lâminas foliares de genótipos de Paspalum spp.

\begin{tabular}{lccc}
\hline ESPÉCIE & EPD & EPB & EPG \\
\hline P. Glucescens & $22,93 \mathrm{D}$ & $7,62 \mathrm{~B}$ & $30,55 \mathrm{D}$ \\
Paspalum sp.1 & $50,33 \mathrm{~A}$ & $7,03 \mathrm{~B}$ & $57,36 \mathrm{~A}$ \\
Paspalum sp.2 & $37,99 \mathrm{C}$ & $9,28 \mathrm{~A}$ & $47,27 \mathrm{~B}$ \\
P. Guenoarum & $40,28 \mathrm{~B}$ & $9,01 \mathrm{~A}$ & $49,29 \mathrm{~B}$ \\
P. Regnellii & $35,29 \mathrm{C}$ & $7,57 \mathrm{~B}$ & $42,86 \mathrm{C}$ \\
P. Malocophyllum & $40,18 \mathrm{~B}$ & $7,53 \mathrm{~B}$ & $47,72 \mathrm{~B}$ \\
P. Guenoarum & $36,65 \mathrm{C}$ & $9,55 \mathrm{~A}$ & $46,21 \mathrm{~B}$ \\
P. Atratum & $39,45 \mathrm{~B}$ & $8,85 \mathrm{~A}$ & $48,31 \mathrm{~B}$ \\
\hline CV(\%) & 6,49 & 6,79 & 5,03 \\
\hline MÉdIA/DP & $37,89 \pm 7,6$ & $8,30 \pm 0,96$ & $46,20 \pm 7,5$ \\
\hline
\end{tabular}

*Médias seguidas de mesma letra na mesma coluna não diferem entre si a $5 \%$ de probabilidade, pelo teste de agrupamento de médias Scott-Knott. EPD=epiderme adaxial, EPB=epiderme abaxial, EPG=epiderme geral, $C V=c 0 e f i c i e n t e$ de variação, DP=desvio padrão. Genótipos em ordem de apresentação na tabela: (BRA-011401), (BRA-011681), (BRA-012700), (BRA-014851), (BRA-019186), (BRA-003077), (BRA-006572), (BRA-009610).

Paspalum glaucescens apresenta maior proporção de tecidos no mesofilo (MES; Fig. 1B; Tab. 4), enquanto Paspalum sp.1 a menor, uma diferença de $51,7 \%$ (Tab. 4). Mas observa-se que $P$. malacophyllum está inserido no segundo grupo com maiores valores de BPF. As forrageiras com maior proporção tecidual no MES são importantes do ponto de vista qualitativo, pois suas células apresentam somente a parede primária e não são lignificáveis (Akin, 1979; Cheng, Fay \& Howarth, 1980), exibindo alta concentração de nutrientes solúveis (carboidratos, proteínas e lipídios). Associadas ao floema, são tecidos que apresentam maior digestibilidade (Akin, 1979; Cheng, Fay \& Howarth, 1980).

As células da BPF têm alto teor de proteína e amido em seu conteúdo, e a parede celular pode estar associada à lignina, o que as torna mais resistentes à degradação, requerendo, inicialmente, ataque físico (Akin \& Rigsby, 1985). Pode-se inferir que lâminas foliares com maior área fotossintética ativa apresentam maior proporção de células de mesofilo, refletindo na boa qualidade do tecido, como ocorre em P. malacophyllum.

$P$. glaucescens apresenta maior proporção de bainha parenquimática do feixe (BPF; Fig. 1B) e 
Paspalum sp.1, a menor (Fig. 1E). A proporção de MES e BPF pode ser indicativa do bom potencial qualitativo das lâminas, pois elas apresentam as células mais digestíveis pela microbiota do rúmen (Akin, 1979; Cheng, Fay \& Howarth, 1980). $\mathrm{Na}$ soma dos tecidos MES+BPF, a maior média ocorre em $P$. glaucescens e a menor em Paspalum sp.1. Essa relação MES+BPF é de grande importância para a digestão da BPF, pois só estará acessível às bactérias após a degradação do MES.
As células da BPF apresentam em seu citoplasma alto teor de proteína e amido, segundo observado em forrageiras estudadas por Wilson (1993). Mas como a BPF é potencialmente digestível, pois sua parede celular é passível de lignificação, não se pode afirmar que esses nutrientes estarão disponíveis aos microrganismos do rúmen, como observado em Paspalum sp.2 e Paspalum glaucescens.

Tab. 4. Proporção relativa (\%) na seção transversal, de lâminas foliares de genótipos de Paspalum spp.

\begin{tabular}{lccc}
\hline ESPÉCIE & MES & BPF & BPF+MES \\
\hline P. Glucescens & $40,27 \mathrm{~A}$ & $19,68 \mathrm{~A}$ & $59,96 \mathrm{~A}$ \\
Paspalum sp.1 & $26,54 \mathrm{E}$ & $11,02 \mathrm{C}$ & $37,56 \mathrm{D}$ \\
Paspalum sp.2 & $28,57 \mathrm{D}$ & $16,01 \mathrm{~B}$ & $44,59 \mathrm{C}$ \\
P. Guenoarum & $33,12 \mathrm{~B}$ & $12,70 \mathrm{C}$ & $45,82 \mathrm{C}$ \\
P. Regnellii & $35,68 \mathrm{~B}$ & $15,54 \mathrm{~B}$ & $51,22 \mathrm{~B}$ \\
P. Malocophyllum & $34,33 \mathrm{~B}$ & $13,09 \mathrm{C}$ & $47,43 \mathrm{C}$ \\
P. Guenoarum & $31,14 \mathrm{C}$ & $15,21 \mathrm{~B}$ & $46,35 \mathrm{C}$ \\
P. Atratum & $34,06 \mathrm{~B}$ & $12,78 \mathrm{C}$ & $46,84 \mathrm{C}$ \\
\hline CV(\%) & 4,04 & 8,94 & 3,84 \\
\hline MÉDIA/DP & $32,96 \pm 4,3$ & $14,50 \pm 2,7$ & $47,47 \pm 6,3$ \\
\hline
\end{tabular}

*Médias seguidas de mesma letra na mesma coluna não diferem entre si a $5 \%$ de probabilidade, pelo teste de agrupamento de médias Scott-Knott. MES=mesofilo, BPF=bainha parenquimática dos feixes, $C V=$ coeficiente de variação, $\mathrm{DP}=$ desvio padrão. Genótipos em ordem de apresentação na tabela: (BRA-011401), (BRA-011681), (BRA-012700), (BRA-014851), (BRA-019186), (BRA-003077), (BRA-006572), (BRA-009610).

Paspalum glaucescens apresenta maior proporção de tecido vascular (TV) e de esclerênquima (ESC, Tab. 5; Fig. 1B), assim como para a soma destes (TV+ESC). Já P. malacophyllum exibe o menor valor de TV e está dentro do grupo com menor valor de ESC e soma dos dois (TV+ESC). O tecido vascular compreende as células de xilema e de floema, sendo estas últimas menores, com arranjo mais compacto do que as de mesofilo, e não apresentam lignina na parede celular, sendo rapidamente digeridas no rúmen (Harbers, Brazle \& Rainten, 1981), ao contrário das células de xilema, cujas paredes lignificadas tornam-se indigestíveis pelo animal (Akin, 1979), desqualificando $P$. glaucescens neste sentido.

Com relação à proporção de ESC, além de ter células indigestíveis, quando se associa à EPI e/ ou à BPF forma a estrutura "girder" (Wilson et al., 1989; Fig. 1f). Segundo este autor, algumas forrageiras apresentam a epiderme apoiada por células de esclerênquima e pelas células da BFV - estrutura "girder" -, o que dificulta o desprendimento da epiderme do restante da folha, fornecendo maior resistência à planta. Este arranjo afeta negativamente a digestibilidade da lâmina foliar, ou seja, implica menor fragilidade digestiva das lâminas, interferindo na gravidade específica das partículas no rúmen (Wilson et al., 1989). A lignina previne a digestão do tecido vascular e diminui a hidrólise de tecidos esclerenquimáticos e epidérmicos. Por isso, a localização e a quantidade de substâncias que impedem a digestão, como lignina e sílica, devem ser consideradas na determinação da qualidade da forragem (Harbers, Brazle \& Rainten, 1981). Como o ESC ocorre em grande quantidade em Paspalum glaucescens, isso acaba interferindo no grau de digestibilidade de suas células. 
Tab. 5. Proporção relativa (\%) na seção transversal, de lâminas foliares de genótipos de Paspalum spp.

\begin{tabular}{lccc}
\hline EsPÉCIE & TV & ESC & TV+ESC \\
\hline P. Glucescens & $5,52 \mathrm{~A}$ & $3,96 \mathrm{~A}$ & $9,48 \mathrm{~A}$ \\
Paspalum sp.1 & $3,28 \mathrm{C}$ & $1,50 \mathrm{C}$ & $4,79 \mathrm{D}$ \\
Paspalum sp.2 & $4,67 \mathrm{~B}$ & $2,47 \mathrm{~B}$ & $7,15 \mathrm{~B}$ \\
P. Guenoarum & $2,74 \mathrm{D}$ & $2,13 \mathrm{~B}$ & $4,87 \mathrm{D}$ \\
P. Regnellii & $3,43 \mathrm{C}$ & $2,47 \mathrm{~B}$ & $5,91 \mathrm{C}$ \\
P. Malocophyllum & $2,22 \mathrm{D}$ & $2,63 \mathrm{~B}$ & $4,85 \mathrm{D}$ \\
P. Guenoarum & $4,45 \mathrm{~B}$ & $2,81 \mathrm{~B}$ & $7,26 \mathrm{~B}$ \\
P. Atratum & $3,19 \mathrm{C}$ & $1,44 \mathrm{C}$ & $4,64 \mathrm{D}$ \\
\hline CV(\%) & 10,13 & 15,15 & 10,98 \\
\hline MÉDIA/DP & $3,69 \pm 1,1$ & $2,43 \pm 0,8$ & $6,12 \pm 1,7$ \\
\hline
\end{tabular}

*Médias seguidas de mesma letra na mesma coluna não diferem entre si a $5 \%$ de probabilidade, pelo teste de agrupamento de médias Scott-Knott. TV=tecido vascular, $E S C=$ esclerênquima, $C V=$ coeficiente de variação, $D P=$ desvio padrão. Genótipos em ordem de apresentação na tabela: (BRA-011401), (BRA-011681), (BRA-012700), (BRA014851), (BRA-019186), (BRA-003077), (BRA-006572), (BRA-009610).
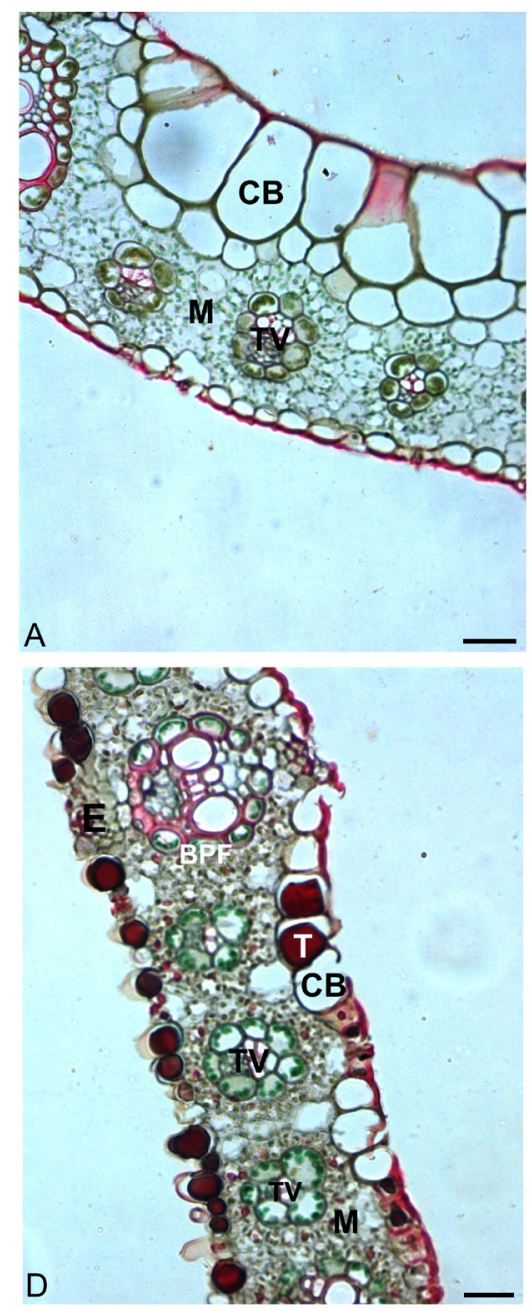
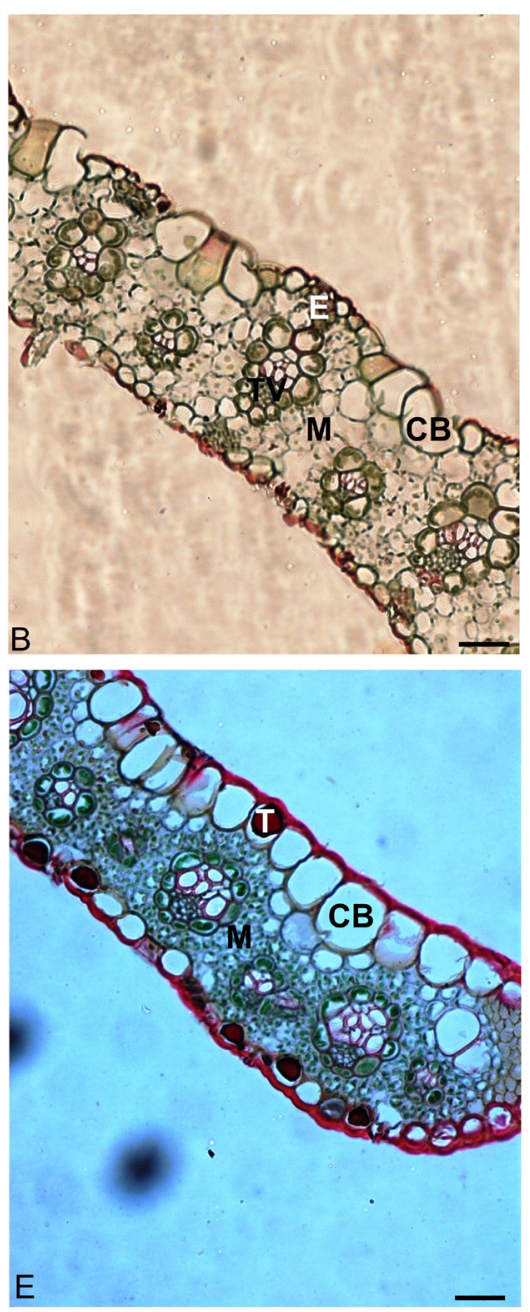

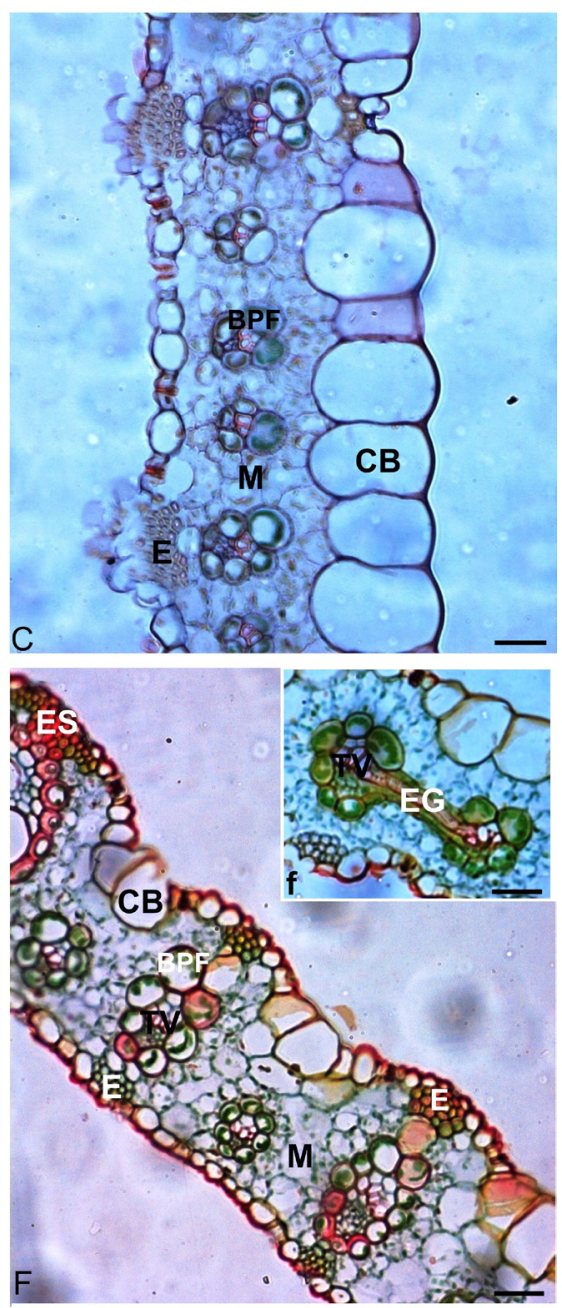

Fig. 1. Seç̧ões transversais da lâmina foliar dos genótipos: Paspalum sp.1 (A); Paspalum glaucescens (B); Paspalum malacophyllum (C); Paspalum sp.2 (D); Paspalum sp.1 (E); Paspalum glaucescens (F) e Paspalum regnelii (f). BPF = bainha parenquimática do feixe; $C B=$ células buliformes; $E=$ esclerênquima; $E G$ = estrutura girder; $M=$ mesofilo; $T$ $=$ tanino; TV = tecido vascular. Escala: A, B, C, D, E, F, f = $100 \mu \mathrm{m}$. 


\section{Conclusões}

As avaliações anatômicas de lâminas foliares de Paspalum spp. indicam importantes diferenças entre os genótipos quanto à proporção e à composição dos tecidos. Paspalum malacophyllum destacou-se em relação às características morfofisiológicas, químicas e anatômicas importantes. Paspalum glaucescens também se destacou em relação à presença de alguns tecidos com importância nutricional, entretanto apresenta estruturas não digestíveis. Com isso, pode-se considerar Paspalum malacophyllum como uma espécie de potencial qualitativo alto para a utilização como forrageira na pecuária. Entretanto, estudos de digestibilidade seriam de importância para resultados mais refinados.

\section{Agradecimentos}

À Fundação de Apoio ao Desenvolvimento do Ensino, Ciência e Tecnologia do Estado de Mato Grosso do Sul (FUNDECT), pela concessão de bolsa ao primeiro autor. À Embrapa Pecuária Sudeste pela disponibilização dos genótipos de Paspalum.

\section{ReferênCIAS}

Akin, D. E. 1979. Microscopic evaluation forage digestion by rumen microorganisms - A review. Journal of Animal Science. 48: 701-710.

Akin, D. E. \& L. L. Rigsby. 1985. Degradation of Bermuda grass. by species of ruminal bacteria. Applied Environmental Microbiology. 50: 825-830.

Aliscioni, S. S. \& M. O. Arriaga. 1998. Estudio histofoliar comparado de los grupos Virgata y Quadrifaria del género Paspalum L. (Poaceae: Panicoideae: Paniceae). Candollea. 53: 333-348.

Aliscioni, S. S. \& S. S. Denham. 2008. Rachis of the genus Paspalum L. (Poaceae: Panicoideae: Paniceae): anatomy and taxonomic significance of the primary branches of the inflorescences. Flora. 203: 60-76.

AOAC - Association of official analytical chemists. 1990. Official methods of analysis. Arlington. 1: 72-74.

Baréa, K., S. M. Scheffer-Basso \& D. Favero. 2006. Desenvolvimento morfológico de Paspalum paniculatum L. (Poaceae). Biotemas 19: 33-39.
Barry, T. N. \& S. J. Duncan. 1984. The role of condensed tannins in the nutritional value of Lotus pedunculatus 1. Voluntary intake. British Journal of Nutrition. 51: 485-491.

Brito, C. J. F. A, R. A. Rodella, F. C. Deschamps \& Y. Alquini. 1999. Anatomia quantitativa e degradação in vitro de tecidos em cultivares de capim-elefante. R. Bras. Zootec. 28: 223229.

Camacho de Torres, E. F., H. Rodriguez \& L. Guevara. 1999. Paspalum remianum Camacho, Rodríguez \& Guevara. sp. nov., Gramineae de Venezuela. Ernstia. 8: 105-114.

Canto-Dorow, T. S. do, H. M. Longhi-Wagner \& J. F. Montenegro Valls. 1996. Revisão taxonômica das espécies de Paspalum L. grupo Notata (Poaceae-Paniceae) do Rio Grande do Sul, Brasil. Iheringia, Série Botânica. 47: 3-44.

Cardoso, E. C., E. Braga, A. P. Camarão, W. C. Moreno, J. Moutinho, S. S. Souza, A. H. H. Minervino \& G. D. G. Ferreira. 2006. Teores de proteína bruta, extrato etéreo e minerais de gramíneas de Paspalum repens e Paspalum fasciculatum de ecossistemas de Várzea do Baixo Amazonas, Pará, Brasil. Pasturas Tropicales. 28: 67-71.

Caro, J. A. \& E. Sanchez. 1969. Las especies de Cynodon (Gramineae) de la Republica Argentina. Kurtziana. 5: 191-252.

Cheng, K. J., J. P. Fay \& R. E. Howarth. 1980. Sequence of events in the digestion of fresh legume leaves by rumen bacteria. Applied and Environmental Microbiology. 40: 613-625.

Daykin, N. E. \& R. S. Hussey. 1985. Staining and histopathological techniques in nematology, p. 39-48. In: K. R. BARKER, C. C. CARTER, \& J. N. SASSER (Ed.). Advance Treatise on Meloidogyne, Releigh, North Caroline State University Grafics.

Filgueiras, T. S., H. N. Longui-Wagner, P. L. Viana, A. Zanin, A. Guglieri, R. C. Oliveira, T. S. Canto-Dorow, R. T. Shirasuna \& J. F. Valls. 2010. Poaceae in lista de espécies da flora do Brasil. Jardim Botânico do Rio de Janeiro.

Gomes, R. A., B. Lempp, L. Jank, G. C. Carpejani \& M. D. G. Morais. 2011. Características anatômicas e morfofisiológicas de lâminas foliares de genótipos de Panicum maximum. Pesquisa Agropec. Bras. 46: 205-211. 
Hagquist, C. W. 1974. Preparation and care of microscope slides. The American Biology Teacher. 36: 414-417.

Harbers, L. H., F. K. Brazle \& D. J. Rainten. 1981. Microbial degradation of smooth brome and tall fescue observed by scanning electron microscopy. Journal of Animal Science. 51: 439-446.

Johansen, D. A. 1940. Plant Micro technique. McGraw-Hill, New York.

Jung, H. G. \& D. A. Deetz. 1993. Cell wall lignification and degradability, p. 315-346. In JUNG, H. G., D. R. BUXTON, R. D. HATFIELD, et al. (Ed.). Forage cell wall structure and digestibility, ASA-CSSA-SSSA, Madison.

Lempp, B. 2007. Avanços metodológicos da microscopia na avaliação de alimentos. R.Bras. Zootec., suplemento especial. 36: 315-329.

Marten, G. C., J. S. Shenk \& F. E. Barton. 1985. Near Infrared Reflectance Spectroscopy (NIRS), Analysis Quality. USDA, Agriculture Handbook, Washington.

Masaoka, Y., J. R. Wilson \& J. B. Hacker. 1991. Selecting for nutritive value in Digitaria milanjiana 3. Relation of chemical composition and morphological and anatomical characteristics to the difference in digestibility of divergently selected full sibs, and comparison with Digitaria eriantha ssp. pentzii (pangola grass). Australian Journal of Experimental Agriculture. 31: 631-638.

Mauseth, J. D. 1988. Plant Anatomy. The Benjamin/Cummings Publishing Company. Inc. California, p.560.

Merchen, N. R. \& L. D. Bourquin. 1994. Process of digestion and factors influencing digestion of forage-based diets by ruminants, p. 564-612. In: FAHEY Jr., G. C. (Ed.). Forage quality, evaluation and utilization, Wisconsin: ASA/CSSA/SSSA, Madison.

Mertens, D. R. 1994. Regulation of forage intake, p. 450-493. In: FAHEY, G. C. Jr.; M. COLLINS, D. R. MERTENS, et al. (Ed.). Forage quality, evaluation and utilization, Madison.

Moore, J. E. \& G. O. Mott. 1973. Structural inhibitors of quality in tropical grasses, p. 53-98. In: MATCHES, A. G. (Ed.). Anti quality components of forages, CSSA, Special publication, Madison, n.4.
Morrone, O., A. S. Vega, F. O. Zuloaga. 1996. Revisión del grupo Dissecta (s.str.) del género Paspalum (Poaceae: Panicoideae: Paniceae). Candollea. 51: 2-34.

Morrone, O., S. S. Denham, F. O. Zuloaga. 2004. Revisión taxonómica del gênero Paspalum grupo Eriantha (Poaceae, Panicoideae, Paniceae). Annals of the Missoure Botanical Garden. 91: 225-246.

Ogie-Odia, E. A., A. I. Mokwenye, O. Kekere \& O. Timothy. 2010. Comparative vegetative and foliar epidermal features of three Paspalum L. species in Edostate, Nigeria. Ozean Journal of Applied Science. 3: 29-38.

Oliveira, R. C. \& J. F. M. Valls. 2002. Taxonomia de Paspalum L., grupo Linearia (Gramineae-Paniceae) do Brasil. Rev.Bras.Bot. 25(4): 371-389.

Paciullo, D. S. C., J. A. Gomide, E. D. Silva, D. S. Queiroz \& C. A. M. Gomide. 2002. Características Anatômicas da Lâmina Foliar e do Colmo de Gramíneas Forrageiras Tropicais, em Função do Nível de Inserção no Perfilho, da Idade e da Estação de Crescimento. R. Bras. Zootec. 31: 890-899.

Quarín, C. L. \& W. W. Hanna. 1980. Chromosome behavior, embryo sac development, and fertility of Paspalum modestum, $P$. boscianum, and $P$. conspersum. Journal of Heredity. 71: 419-422.

Radford, P. J. 1967. Growth analysis formulae their use and abuse. Crop Science. 7: 171-5.

Scheffer-Basso, S. M. \& M. M. Gallo. 2008. Aspectos morfofisiológicos e bromatológicos de Paspalum plicatulum. R. Bras. Zootec. 37(10): 1758-1762.

Scheffer-Basso, S. M., G. L. Rodrigues \& M. V. Bordignon. 2002. Caracterização Morfofisiológica e Anatômica de Paspalum urvillei (Steudel). R. Bras. Zootec. 31(4): 16741679.

Sisvar software. 2003. versão 4.6. Ferreira, D. Lavras: DEX/UFLA. Software.

Sniffen, C. J., R. W. Beverly, C. S. Mooney, M. B. Roe, A. L. Skidmore \& J.R. Black. 1993. Nutrient requirements versus supply in the dairy cow: strategies to account for variability. Journal of Dairy Science. 76: 3160-3178. 
Strapasson, E., R. Vencovsky \& L. A. R. Batista. 2000. Seleção de descritores na caracterização de germoplasma de Paspalum sp. por meio de componentes principais. R. Bras. Zootec. 29: 373-381.

Valls, J. F. M. \& R. C. de. Oliveira. 2012. Paspalum in Lista de Espécies da Flora do Brasil. Jardim Botânico do Rio de Janeiro.

Van Soest, P. J., J. B. Robertson \& B. A. Lewis. 1991. Methods for dietary fiber, neutral detergent fiber, and nonstarch polysaccharides in relation to animal nutrition. Journal of Dairy Science. 74: 3583-3597.

Van Soest, P. J. 1994. Nutritional ecology of the ruminant. 2 ed. Nueva York. Cornell University Press. p.476.

Vilela, L., A. O. Barcellos \& R. P. Andrade. 2001. Calagem e Adubação para o Capim-Pojuca. Rec. Téc.- Embrapa Cerrados, Planaltina. 25: 1-2.
Wilson, J. R., K. L. Anderson \& J. B. Hacker. 1989. Dry matter digestibility in vitro of leaf and stem of buffel grass (Cenchrus ciliares) and related species and its relation to plant morphology and anatomy. Australian Journal of Agricultural Research. 40(2): 281-291.

Wilson, J. R. 1993. Organization of forage plant tissue, p. 1-27. In: JUNG, H. G., D. R. BUXTON, R. D. HATIFIELD, J. RALPH (Ed.). Forage cell wall structure and digestibility. Madison: American Society of Agronomy, Crop Science Society of America, Soil Science Society of America, Madison, Wisconsin.

Zuloaga, F. O. \& O. Morrone. 2005. Revisión de las especies de Paspalum para América del Sur austral (Argentina, Bolivia, sur del Brasil, Chile, Paraguay y Uruguay). Monographs in systematic botany from the Missouri Botanical Garden, v.102. 